\title{
REFLEXÕES SOBRE A PARTICIPAÇÃO SOCIAL NA GESTÃO HÍDRICA NO BRASIL
}

\author{
Márcia Eliane Silva Carvalho ${ }^{1}$, Odirley Batista Moreira²
}

(1 - Universidade Federal de Sergipe, Docente do Departamento de Geografia e Mestrado Profissional em Rede Nacional para o Ensino das Ciências Ambientais (PROF-CIAMB/UFS), E-mail: marciacarvalho_ufs@yahoo.com.br; 2 - Universidade Federal de Sergipe, Geógrafo, Professor da Secretaria Estadual de Educação de Sergipe (SEED), Mestrando da Rede Nacional para o Ensino das Ciências Ambientais (PROF-CIAMB/UFS), E-mail: odirley26@hotmail.com)

Resumo: Este artigo tem como objetivo apresentar reflexões sobre a participação social na gestão dos recursos hídricos, analisando se esse convite à sociedade trata-se de transformações no paradigma de pensamento dominante ou se tais mudanças encontram respaldo somente na legislação e como poucas alterações no modelo vigente. Para atingir o objetivo proposto foi realizada uma revisão da literatura sobre a temática, tomando como base as considerações de Morin (2000), Tundisi (2005), Guerra et.al. (2005), Jacobi e Barbi (2007), Leff (2000, 2009), dentre outros. Os passos mais consistentes na direção de incluir as populações locais na gestão dos recursos hídricos vêm se delinear com mais clareza a partir da década de 1990. Embora com os avanços registrados na implementação e operacionalização das instâncias participativas coletivas, a exemplos dos Comitês de Bacias Hidrográficas, um dos gargalos encontra-se na fragilidade das organizações coletivas e da sociedade civil, bem como a resistência de certos segmentos e setores de usuários tradicionalmente privilegiados (grandes agricultores e indústrias) que se caracterizam como entraves para o pleno exercicio de democratização ao uso e a gestão das águas, fazendo-se necessário o fortalecimento das organizações que representam a sociedade excluída do processo capitalista global.

Palavras chave: Gestão democrática - Sociedade - Espaços Coletivos de Atuação Social

\footnotetext{
Artigo recebido para publicação em 12 de Janeiro de 2017 Artigo aprovado para publicação em 18 de Junho de 2017
} 


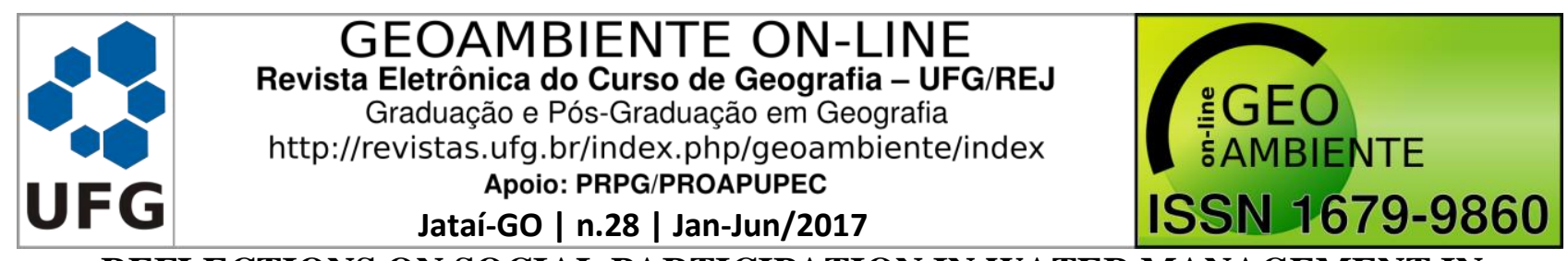

REFLECTIONS ON SOCIAL PARTICIPATION IN WATER MANAGEMENT IN

BRAZIL

Abstract: This article aims to present reflections on social participation in the management of water resources, analyzing whether this invitation to society is about transformations in the dominant thinking paradigm or whether such changes are supported only in legislation and as few changes in the current model. In order to reach the proposed objective, a review of the literature on the subject was made, based on the considerations of Morin (2000), Tundisi (2005), Guerra et.al. (2005), Jacobi and Barbi (2007), Leff (2000, 2009), among others. The most consistent steps towards including local populations in water resources management have been more clearly delineated since the 1990s. Although with the progress made in the implementation and operation of collective participatory bodies, examples from the Watershed Committees, one of the bottlenecks is the fragility of collective organizations and civil society, as well as the resistance of certain segments and sectors of traditionally privileged users (large farmers and industries) that are characterized as obstacles to the full exercise of democratization in the use and water management, making it necessary to strengthen the organizations that represent the society excluded from the global capitalist process.

Keywords: Democratic management - Society - Collective spaces of social action

\section{REFLEXIONES SOBRE LA PARTICIPACIÓN SOCIAL EN LA GESTIÓN DEL AGUA EN BRASIL}

Resumen: Este artículo tiene como objetivo presentar reflexiones sobre la participación social en la gestión de los recursos hídricos, considerando si esta invitación a la sociedad son los cambios en el paradigma de pensamiento dominante o si tales cambios están respaldados únicamente por la ley y el menor número de cambios en el modelo actual. Para lograr este propósito se llevó a cabo una revisión de la literatura sobre el tema, sobre la base de las consideraciones de Morin (2000), Tundisi (2005), Guerra et.al. (2005), Jacobi y Barbi (2007), Leff (2000, 2009), entre otros. Los pasos más consistentes en la dirección para incluir la población local en la gestión de los recursos hídricos vienen a delinear con mayor claridad a partir de la década de 1990. A pesar de los avances logrados en la implementación y puesta en funcionamiento de instancias de participación colectiva, ejemplos de los Comités de Cuencas, uno de los cuellos de botella es la debilidad de las organizaciones colectivas y de la sociedad 
civil, así como la resistencia de ciertos segmentos y sectores privilegiados tradicionalmente por el usuario (grandes agricultores e industrias) que se caracterizan como impedimentos para el ejercicio pleno de la democracia y de utilizar la gestión del agua, por lo que es necesario reforzar las organizaciones que representan el proceso global de la sociedad capitalista excluidos.

Palabras clave: gestión democrática - Sociedad - espacios colectivos de Actividades Sociales

\section{Introdução}

Desde meados do século passado que a humanidade percebeu que o modelo dominante de reprodução da nossa sociedade, nosso modelo sócio-econômico entrou em crise e esbarrou nos efeitos de suas contradições e nos limites da capacidade do nosso planeta de suportar o ritmo de exploração de componentes vivos e não-vivos da natureza, componentes esses que ideologicamente chamamos de "recursos", que nada mais é do que uma forma simbólica de apropriação.

A evidência de uma dupla crise, a do pensamento e a ambiental, que se anuncia no horizonte próximo, nos tange à necessidade de abordar temas antes invisíveis nas pautas das discussões mundiais. Diversas conferências internacionais foram realizadas com o intuito de fazer com que os países do globo unifiquem ações e promovam mudanças no sentido de garantir a existência das condições para que gerações presentes e futuras continuem a habitar este planeta.

\footnotetext{
A humanidade se encontra em um momento de definição histórica. Defrontamo-nos com a perpetuação das disparidades existentes entre as nações e no interior delas, o agravamento da pobreza, da fome, das doenças e do analfabetismo, e com a deterioração contínua dos ecossistemas de que depende o nosso bem-estar (ONU, 1992, p.11).
}

Dentro desse conjunto de problemas, encontramos, ocupando um dos papéis centrais, a questão hídrica. Há uma relação clara entre disponibilidade de água e desenvolvimento econômico e um dos principais problemas criados foi justamente por conta da sua má distribuição e deficiência no saneamento para boa parte da população mundial (TUNDISI, 2005).

A água, por natureza, não se encontra distribuída equitativamente por todos os lugares do planeta, a dinâmica hidrológica, associada a condições geológicas, climáticas e econômicas, privilegiou algumas áreas em detrimento de outras.Somado a essa questão ainda 
temos a ação antrópica gerando fortes impactos e interferências no ciclo da água e consequentemente na sua disponibilidade em quantidade e qualidade. Atualmente, os diversos usos múltiplos da água impulsionado pela pressão demográfica, pelas demandas industriais e agrícolas tem ampliado cada vez mais a necessidade de planejamento sobre os mananciais (TUNDISI, 2005).

Enquanto elemento essencial à manutenção da vida no planeta, ao funcionamento de nossa sociedade e de nossa economia, a água se tornou alvo de preocupação coletiva e consequentemente preocupação de governos que passaram a discuti-la dentro das grandes pautas ambientais, traçando, a partir dessas discussões e debates, políticas públicas, tratados e legislações responsáveis por regulamentar o uso múltiplo desse elemento que se encontra cada vez mais raro.

Assim, tornou-se inviável pensar em gestão dos recursos hídricos desvinculada de questões pertinentes ao uso do solo e a ocupação humana. Em função destes fatos, a bacia hidrográfica tem sido tomada como unidade de planejamento e manejo dos recursos naturais por ser uma unidade conveniente ao entendimento da ação dos processos hidrológicos, geomorfológicos e antrópicos.

As bacias hidrográficas vêm sofrendo toda sorte de intervenção e danos: descarte de efluentes residencial, industrial, comercial e agrícola, construção de inúmeros barramentos, alteração em seu curso, transposição de suas águas e retirada da vegetação ao longo das margens de seus leitos e no entorno de suas nascentes. Esse quadro move governos e sociedade civil no mundo inteiro.

Associado a estas questões encontra-se a figura do Estado, como órgão gestor dos recursos hídricos, que busca, através dos princípios de democratização do acesso ao uso da água e do aumento da participação da sociedade civil organizada, compartilhar as decisões e ações no âmbito da gestão das águas. Assim, um dos grandes desafios das políticas públicas na atualidade está ligada à gestão racional e participativa dos recursos hídricos, pois a água além de ser essencial para a sobrevivência do ser vivo, é um recurso limitado e base indispensável para a maioria das atividades produtivas humanas(CARVALHO, 2010).

Neste sentido, este artigo tem como objetivo apresentar reflexões sobre a participação social na gestão dos recursos hídricos. Em tempo, analisa-se se esse convite à sociedade civil é na verdade um intuito de transformações no paradigma de pensamento dominante, que busca abrir espaço à novos caminhos mais democráticos no processo de gestão, ou se tais 


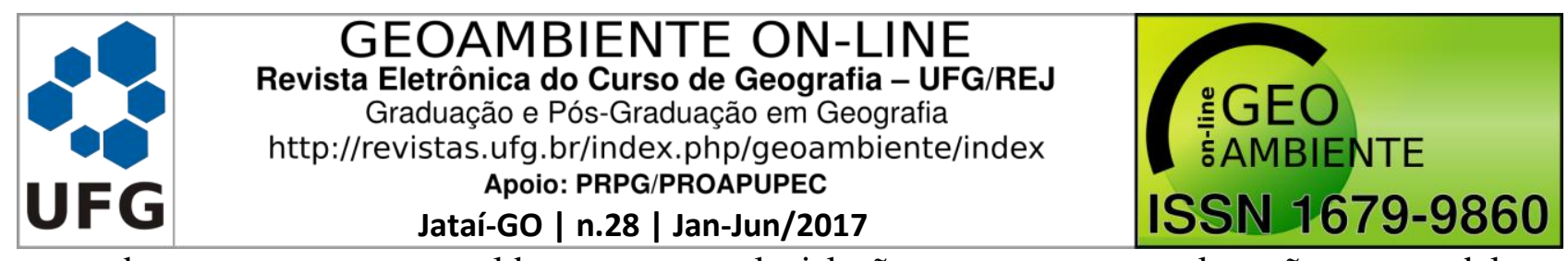

mudanças encontram respaldo somente na legislação e como poucas alterações no modelo vigente.

Para atingir o objetivo proposto foi realizada uma revisão da literatura sobre a temática, tomando como base as considerações de Morin (2000), Tundisi (2005), Guerra et.al. (2005), Jacobi e Barbi (2007), Leff (2000, 2009), dentre outros.

\section{Legislação e Participação Social na Gestão dos Recursos Hídricos}

Apesar do Brasil já possuir leis que abordam a questão da água desde 1934 quando foi instituído o primeiro código de águas (Lei 24.643/34), este deixava nas mãos do poder público a competência de gerir os recursos hídricos em território nacional quando diz que entre outras considerações “....resolve decretar o seguinte código de águas, cuja execução compete ao ministério da agricultura e que vai assinado pelos ministros de Estado".Mesmo na Constituição de 1988 em seu art. 22, onde no inciso IV diz que compete privativamente à União legislar sobre “águas, energia, informática, telecomunicações e radiodifusão”.

Os passos mais consistentes na direção de incluir as populações locais na gestão dos recursos hídricos vêm se delinear com mais clareza a partir da década de 1990, o que se pode averiguar ainda no artigo $1^{\circ}$, inciso VI da Lei 9.344/97, onde fica definido com mais clareza esse espaço à participação, pois diz que "a gestão dos recursos hídricos deve ser descentralizada e contar com a participação do Poder Público, dos usuários e das comunidades".

A partir de então a participação pública se torna uma das principais características adotadas pelo sistema integrado de gestão instituído a partir da lei 9.344/97. Como afirma Tundisi (2005, p.146), “Outra característica relevante do sistema é a importância dada à participação pública. Garantiu-se a participação de usuários e da sociedade civil em todos os plenários constituídos pelo sistema[...]”.

O corpo da lei 9.795/99, criada dois anos após o novo código de águas e que versa sobre a educação ambiental, vem totalmente revestida com a visão participativa e democrática da gestão ambiental. No inciso I do art. $4^{\circ}$ desta mesma lei está posto que entre os princípios básicos da educação ambiental está "o enfoque humanista, holístico, democrático e participativo".

No artigo $4^{\circ}$ que versa ainda sobre os princípios básicos da educação ambiental está dito no inciso VIII a necessidade de se estabelecer o "reconhecimento e o respeito à pluralidadee à diversidade individual e cultural". Esse é um dos aspectos que marca uma 
sociedade realmente democrática e que permite a participação plena dos cidadãos. De acordo com Morin (2000, p. 108):

\begin{abstract}
A democracia supõe e nutre a diversidade dos interesses, assim como a diversidade de idéias. O respeito à diversidade significa que a democracia não pode ser identificada como a ditadura da maioria sobre as minorias; deve comportar o direito das minorias e dos contestadores à existência e à expressão e deve permitir a expressão das idéias heréticas e desviantes.
\end{abstract}

Há uma idéia de que o projeto dominante, vencedor, encerrado em um processo eleitoral, deve se impor sobre tudo e sobre todos, projeto esse na maioria das vezes defensor do grande capital e de sua lógica de exploração. Mas a democracia é um processo dialógico e exige ouvir diversas vozes. Para Morin (2000, p. 107) “A democracia fundamenta-se no controle da máquina do poder pelos controlados [...]”. Por isso a importância de uma legislação que ofereça a oportunidade, dentro de espaços legais, das populações locais, dos povos tradicionais definirem seus rumos, definirem o modelo de exploração dos seus recursos, o modelo de relação entre homem e meio, dentro dos seus espaços de vivência. Diminuindo assim a possibilidade de que mãos poderosas se sobreponham à vontade e prioridades locais. É nesse sentido que se pode afirmar que a legislação ambiental brasileira deu importantes passos quando abriu à participação social.

A importância dessa abertura legal para a presença e participação da sociedade civil nos espaços oficiais de decisões reside no fato de que são eles,que vistos de forma separadas dentro de suas localidades são rotulados como minoria, os que mais sofrem os efeitos e impactos da degradação ambiental, principalmente dos recursos hídricos. São os sujeitos sociais que vivem e usam aquele determinado espaço, que estão ali há gerações os que mais tem a perder.

Já o agente responsável por essa lógica de exploração marcada pela degradação desses espaços é uma entidade móvel. O capital, grande motor desse paradigma dominante, possui enorme mobilidade e por essa razão pode escolher novos territórios para explorar e assim não interromper sua reprodução. As populações autóctones, tradicionais não gozam desse privilégio, as únicas opções são ficar e arcar com o alto custo de viver em um espaço descaracterizado, que não possui mais a capacidade de garantir sua sobrevivência ou partir para as grandes aglomerações urbanas viver em condições geralmente precárias.

Neste viés, pensar em democratização e participação social seria também uma tentativa de mudança em direção ao desenvolvimento sustentável? Ou pensar em sociedades sustentáveis como aborda Tristão (2008)? 
Em que pese a importância do desenvolvimento sustentável na gestão territorial, visando democratizar o uso dos bens naturais, é importante, por outro lado, ressaltá-lo enquanto possível instrumento político-ideológico regulatório, ao tentar ordenar o uso do território de acordo com interesses externos às necessidades locais.

Mesmo diante de contradições acerca da dimensão ideológica do termo desenvolvimento sustentável, bem como os caminhos para atingi-lo, e diante do cenário atual de uso não racional dos recursos naturais, não podemos esquecer de que

(...) a sustentabilidade é vista como um paradigma no sentido de rever as interações da sociedade com a natureza, convertendo-se na bússola para a implementação dos processos de planejamento e gestão ambiental e territorial. Isto exige a aplicabilidade de sólidas fundamentações teóricas e metodológicas, sustentadas em visões holísticas, integradoras e sistêmicas das unidades ambientais naturais e sociais (RODRIGUEZ e SILVA, 2002, p. 95).

Para Leff (2009, p. 64)

(...) a transição para um desenvolvimento sustentável não se fará por força da necessidade ou do instituto de sobrevivência da sociedade. A história mostrou ad nauseam e ad mortem as ideologias, os interesses e o poder são capazes de burlar os mais elementares princípios morais de convivência pacifica entre os humanos. Estas mudanças não serão alcançadas sem uma complexa estratégia política, orientada pelos princípios de uma gestão democrática do desenvolvimento sustentável, mobilizada pelas reformas do Estado e pelo fortalecimento das organizações da sociedade civil.

$\mathrm{Na}$ verdade, esse processo de construção de espaços legais de participação, de descentralização da gestão de recursos naturais entre eles os recursos hídricos não é fruto do acaso ou de voluntarismo político. Ao longo da segunda metade do século XX a formulação de caminhos para dar resposta à crise do paradigma dominante construiu o alicerce teórico de toda essa legislação que hoje rege a gestão dos recursos hídricos tanto no Brasil como em diversos países do mundo. De acordo com Leff (2009, p.96):

O custo social da destruição ecológica e da degradação ambiental gerada pela maximização do lucro e dos excedentes econômicos a curto prazo deram pois impulso à emergência de novos atores sociais mobilizados por valores, direitos e demandas que orientam a construção de uma racionalidade ambiental.

O modelo de desenvolvimento dominante impôs uma lógica de exploração dos recursos naturais que, desde a segunda metade do século passado, enfrenta seus limites impostos pelas diversas crises existentes: crise energética, crise da produção de alimentos, crise hídrica. Ainda se tem os custos sociais e ambientais impostos pela concentração urbanoindustrial. No entanto não há uma percepção homogênea da crise ambiental e de suas 
manifestações, e por essa razão não cabe uma única solução, um único discurso e ações unificadas para a solução da crise (LEFF, 2009).

Se as percepções são diferenciadas, podemos usar isso como ponto de apoio teórico para sustentar a idéia das gestões descentralizadas dos recursos ambientais, no caso específico do que tratamos aqui, gestão dos recursos hídricos. Há de se convir que aqueles que vivem e usam um determinado espaço tem o direito de gerir os recursos ali existentes a partir de uma lógica que priorize as necessidades humanas, as demandas sociais. Ainda utilizando essa linha de pensamento, Leff (2009, p. 98) afirma que:

\begin{abstract}
A ativação desse potencial ambiental para um desenvolvimento sustentável implica a necessidade de gerar as condições econômicas e políticas que permitam a participação comunitária na definição de suas necessidades, na autogestão de seus recursos e na produção de seus satisfatores, assim como na inovação, assimilação e adaptação de tecnologias ecologicamente adaptadas. Desta maneira, o conceito de ambiente promove um desenvolvimento sustentável e equitativo, baseado na autonomia cultural, na autodeterminação tecnológica e na independência política dos povos.
\end{abstract}

Mais uma vez fica evidente que a legislação que hoje rege a gestão dos recursos hídricos no Brasil possui profunda influência nesse pensamento que prega a autonomia na gestão social dos recursos naturais entre eles os recursos hídricos. A descentralização dessa gestão oferece oportunidade de autodeterminação das comunidades, das populações locais e de povos tradicionais.

As discussões internacionais que aconteceram na segunda metade do século XX e que culminaram na confecção de uma agenda de compromissos mais conhecida como Agenda 21, foi base de orientação para boa parte do que, posteriormente se consolidou como legislação em diversos países do mundo inclusive aqui no Brasil. O próprio processo de concepção da Agenda 21 deixa clara a tendência de se ampliar os espaços de decisões. Conforme coloca Novaes (2008, p. 323) a Agenda 21:

É um processo de participação em que a sociedade, os governos, os setores econômicos e sociais sentam-se à mesa para diagnosticar os problemas, entender os conflitos envolvidos e pactuar formas de resolvê-los, de modo a construir o que tem sido chamado de sustentabilidade ampliada e progressiva.

Com a criação e regulamentação dos Comitês de Bacias Hidrográficas, através das Leis 9.433/97 e 9.984/2000, a sociedade civil apresenta delineado em lei o seu espaço de atuação. Fica instituído a partir de então o arcabouço legal que determina o modo de atuação 

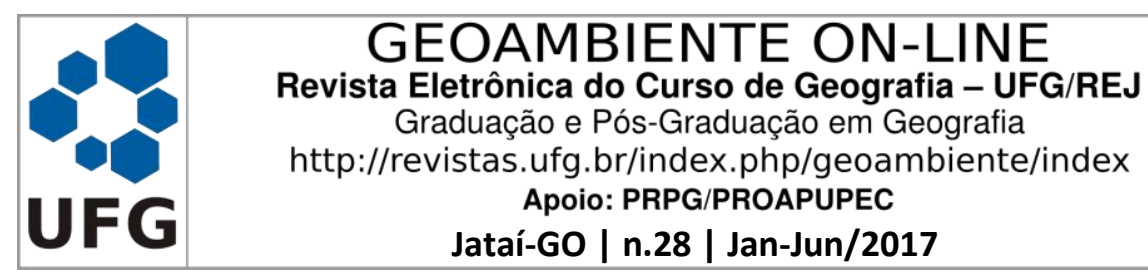

pela qual a população poderá participar do gerenciamento dos recursos hídricos existentes em seus espaços de vivência.

\section{Bacia Hidrográfica como unidade de gestão territorial: um primeiro passo}

A crise hídrica, por sua importância, mobilizou e ainda mobiliza governos na direção de debater, criar e implementar políticas públicas e legislações que regulamentem os usos múltiplos e o manejo das águas subterrâneas e de superfície.Dentro desse contexto, a bacia hidrográfica surge como ponto central e norteador desse esforço e planejamento políticoterritorial da gestão dos recursos hídricos.

De acordo com Guerra et. al. (2005, p. 270) "Entende-se como bacia hidrográfica ou bacia de drenagem a área da superfície terrestre drenada por um rio principal e seus tributários, sendo limitado pelos divisores de água". Para o referido autor, pode-se dizer que a "bacia hidrográfica é uma célula natural que pode, a partir da definição do seu outlet ou o ponto de saída, ser delimitada sobre uma base cartográfica que contenha cotas altimétricas [...] ou que permita uma visão tridimensional da paisagem" (GUERRA, et.al.,2005, p. 270).

Ao contrário do que se pensa, a concepção de bacia hidrográfica como unidade de planejamento territorial já é bastante antiga, datando da primeira metade do século XX onde nos EUA com a criação do Tennessee Valley Authority(TVA) em 1933 aponta para a adoção desse mecanismo como instrumento de gestão territorial, a partir dos EUA outras nações tomaram a mesma atitude: França, Reino Unido (GUERRA et. al., 2005).

Mas foi apenas no final da década de 1990 que se caminhou na direção de compreender a bacia hidrográfica como instrumento de planejamento e gestão territorial dos recursos hídricos. De acordo com a Lei 9.344, em seu artigo $1^{\circ}$, inciso V “a bacia hidrográfica é a unidade territorial para implementação da Política Nacional de Recursos Hídricos e atuação do Sistema Nacional de Gerenciamento de Recursos Hídricos”. A legislação brasileira trata a bacia hidrográfica "como um território de atuação de políticas públicas, além de ser unidade básica para a instalação de sistemas de gerenciamento de recursos hídricos" (BERNARDI et. al., 2012).

Nestes termos, a bacia hidrográfica tem sido apontada por vários autores (dentre eles, LEAL, 2000; SETTI, 2001; CARRERA-FERNANDEZ, 2002; CAMPOS, 2003; MACHADO, 2003; TUNDISI, 2005; SILVA e PRUSKI, 2005; REBOUÇAS, 2006), como a unidade territorial de planejamento e gestão dos recursos hídricos, devido à repercussão integrada dos agentes naturais e antrópicas no espaço em questão. 
É importante ressaltar que o recorte da bacia hidrográfica não atende aos critérios de delimitação físico-administrativa dos municípios, estados ou países. Desta forma, as ações e o diálogo entre tais unidades administrativas deve permear a política relativa a gestão hídrica, aspecto este que pode tanto permitir o diálogo quanto ser um aspecto que restringirá a efetiva gestão hídrica participativa.

Com a implementação da Lei9.433/97 e das legislações em âmbito estaduais que versam sobre a temática, os Comitês de Bacias Hidrográficas ganharam ênfase, no sentido de buscar efetivar o disposto na legislação pertinente à questão. Os fundamentos previstos estabelecem que a gestão dos recursos hídricos deve ser descentralizada e contar com a participação do poder público, dos usuários e da comunidade, buscando efetivar o caráter democrático da legislação em vigor.

Assim, a criação dos Comitês de Bacias Hidrográficas é tomado como o principal colegiado na gestão das águas, visando ter ampla participação da sociedade, tomando como unidade de atuação a bacia hidrográfica, visando gerir os recursos hídricos de forma descentralizada, participativa e integrada, com atribuições consultivas e deliberativas, contando com a participação dos usuários de água, da sociedade civil organizada e dos poderes públicos em nível municipal,estadual e federal,

Ranços e Avanços da Participação Social relativa aos Recursos Hídricos: algumas reflexões

A água é um recurso, tanto quanto os outros, indispensável à sobrevivência dos seres humanos e o uso racional da mesma se faz urgente, sendo que novas proposta de planejamento necessitam ser efetivadas.

Assim, para o planejamento superar tais limitações necessita romper com esta visão e apresentar uma abordagem sistêmica visando compatibilizar, num determinado espaço e tempo, os recursos do território, a sociedade ali instituída e a necessidade de desenvolvimento local.

Segundo Mantovaneli Júnior (2006, p. 75), a questão do planejamento estratégico deve estar associadas a uma visão sistêmica da realidade, sendo este o caminho que deve seguir o processo de planejamento e gestão hídrica, pois abre

(...) a perspectiva de uma leitura onde as organizações devem encarar sua realidade, reconhecendo sua interdependência com a totalidade do ambiente (indo além do sentido estrutural-funcional do conceito), colocando-se como sistemas abertos à sociedade com a qual compartilham seus atores e valores. 


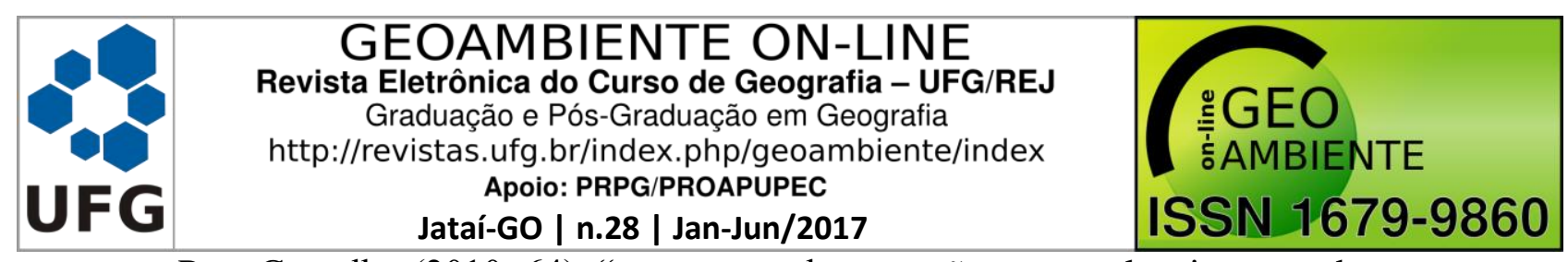

Para Carvalho $(2010,64)$, “...compreende-se, então, que o planejamento dos recursos hídricos inicia uma nova cultura de uso das águas, no qual visa minimizar não só a degradação do ambiente, mas também exclusão social, a partir do momento que engloba a perspectiva física associada ao componente humano".

Assim, no que concerne à questão das águas, a gestão dos recursos hídricos deve considerar a ligação estreita existente entre os problemas de quantidade e de qualidade das águas, bem como deve processar-se no quadro do ordenamento do território, visando a compatibilização, nos âmbitos regional, nacional e internacional, do desenvolvimento econômico e social com os valores do ambiente, conforme ressalta Orlando (2006, p. 30):

(...) a gestão hídrica é entendida como as ações voltadas para gerir, administrar os recursos hídricos, considerando-os em si mesmos e também concomitantemente, como parte dinamicamente ligada aos demais recursos presentes no território.

Neste sentido, a gestão das águas pode ser compreendida como

Um conjunto de procedimentos organizados no sentido de solucionar os problemas referentes ao uso e ao controle dos recursos hídricos. O objetivo da gestão é atender, dentro das limitações econômicas e ambientais e respeitando os princípios de justiça social, a demanda da água pela sociedade com uma disponibilidade limitada. A gestão é formada por três sub-funções: o planejamento, a administração e a regulamentação (CAMPOS, 2003, p. 20).

Assim, a gestão dos recursos hídricos requer uma outra dimensão para o entendimento da questão, pois

\begin{abstract}
Não se trata mais apenas de estabelecer padrões para emissões de poluentes ou fiscalizar o cumprimento de normas técnicas e punir aqueles que infringindo-as, poluem o meio ambiente, embora não se possa prescindir dessas medidas. Aos governos, em especial, mas também às sociedades, de forma ampla, é atribuída a responsabilidade pela promoção de uma atitude nova frente aos recursos naturais e aos problemas ambientais (MACHADO, 2003, p.125).
\end{abstract}

Ao mesmo tempo, Leff (2009) alerta que mudanças na estrutural estatal e no fortalecimento das organizações não governamentais são primordiais para se alcançar uma relação sociedade / natureza menos degradante.

Nesta perspectiva Leal (2000, p. 7) afirma que:

(...) a nova gestão das águas surge como uma possibilidade de intervenção no atual modelo de sociedade, contribuindo para a construção de novas relações sociedade/natureza e superação da crise hídrico-ambiental, assim como para a sustentabilidade do desenvolvimento e a compatibilização do uso e ocupação do solo com a conservação das águas nas bacias hidrográficas 
No plano teórico a legislação contempla princípios da gestão das águas de âmbito universal, mas uma análise mais crítica da mesma revela contradições.

Uma delas reside no fato de que a sociedade não está preparada para assumir os papéis de participação e de gestão do seu espaço, até mesmo em função da histórica ausência de participação cidadã nas decisões políticas. Neste jogo de partilhar obrigações sem dotar a sociedade de informações ou instrumentos cabíveis para tal, questões emergentes, a exemplo da socioambiental, ficam postas de lado. Há o discurso da participação, mas a realidade é expressa de forma contrária.

Esta redemocratização e/ou descentralização, associada ao contexto da crise do Estado inaugura um período de transição com a ruptura do padrão de financiamento do setor público e a perda por parte do Estado de definir interesses regionais que possam fortalecer o discurso da presença necessária da sociedade civil, esta que é chamada para administrar suas próprias demandas (LISBOA, 2007, p. 139).

Revestida de caráter neoliberal, a legislação em pauta (em âmbito federal e nas estaduais) pertinente aos recursos hídricos legitima um Estado descentralizado, mas que atua como gestor das águas, determinando os usos e os fiscalizando, e que por outro lado dissemina a ideia de participação, que em muitos casos não se efetiva. Este é um dos grandes gargalos da gestão hídrica (CARVALHO, 2010).

Oliveira (2010) traz para o debate as contradições entre a questão da governança e a participação social, pois para a autora é o Estado que determina quem, quando, por quanto tempo e que tipo de consumo se dará para determinado corpo hídrico. Há, portanto, um falso discurso da responsabilidade social, que mascara interesses particulares (capitalistas).

A autora supracitada ressalta também, assim como Ribeiro (2008) e Orlando (2006), dentre outros, que a legislação citada regulamentou a água como mercadoria, em função da mesma ser designada como um bem econômico.

Para Pinheiro Filho (2005), as fragilidades das organizações coletivas das comunidades e grupos da sociedade civil, bem como a resistência de certos segmentos e setores de usuários tradicionalmente privilegiados são entraves para o pleno exercicio de democratização ao uso e a gestão das águas.

Na mesma linha de pensamento Jacobi e Barbi (2007, p. 239) apontam que

Os mecanismos para a democracia deliberativa, entendida como modelo ou ideal de justificação do exercício do poder político pautado no debate público entre cidadãos livres e em condições iguais de participação e relacionados com questões 
ambientais, avançaram. Entretanto, ainda não incorporaram os grupos sociais normalmente excluídos dos mecanismos tradicionais de deliberação como atores com presença nos processos decisórios. Isto decorre do fato que estes grupos ainda não possuem os recursos econômicos e sociais e as informações que permitiriam sua participação nas atividades que permeiam processos decisórios em torno de questões ambientais.

No entanto, é importante destacar que a água também é caracterizada como um bem público, finito e não alienável, cujos usos degradantes atuais se tornarão irreversíveis em função do crescimento populacional e da necessidade premente de novos espaços tanto para a reprodução social quanto para a própria produção de alimentos, fazendo-se mister ações visando minimizar este estágio de degradação atual.

Entende-se também que, se por um lado, o Estado mantém seu papel de controle sobre os usos dos recursos hídricos via os instrumentos de gestão constantes no Artigo $5^{\circ}$ da Lei 9433 (os planos de recursos hídricos, o enquadramento dos corpos de água, a outorga e cobrança pelo direito de uso, a compensação a municípios e instituição do Sistema de Informação sobre recursos hídricos), por outro, estes mesmos instrumentos têm papel importante: visam adequar os usos à qualidade das águas dos corpos hídricos, minimizando a degradação dos mesmos via investimento a partir da cobrança pelo seu uso a qual deve ser revertida na própria bacia hidrográfica e manutenção de uma base de dados atualizada sobre sua riqueza hídrica.

Da mesma forma, se por um lado há o reconhecimento do controle estatal sobre as águas, por outro deve-se afirmar que com a efetivação dos Comitês de Bacia Hidrográfica, definindo as prioridades de usos na bacia, possibilita a participação da sociedade minimizando os interesses particulares, além de fornecer dados para o órgão gestor deliberar os usos, que a priori devem ser estabelecidos no plano de recurso hídrico da bacia, construído pelo próprio Comitê de Bacia Hidrográfica.

Os Comitês de Bacias Hidrográficas são compostos por representantes da sociedade civil organizada, usuários de água e pelo poder público, cujas ações visam, dentre outros objetivos, identificar, analisar e avaliar prioridades e interesses no âmbito da bacia acerca dos recursos hídricos locais.

Em casos de bacia de rio federal, a atuação cabe a Agência Nacional de Águas (ANA), criada pela Lei 9.984/2000. Esta agência tem caráter regulador na solução de problemas interestaduais de forma a disciplinar a utilização dos rios, visando resolver conflitos, controlar a poluição e o desperdício, instituído os Comitês de âmbito federal, dentre outras atribuições. 


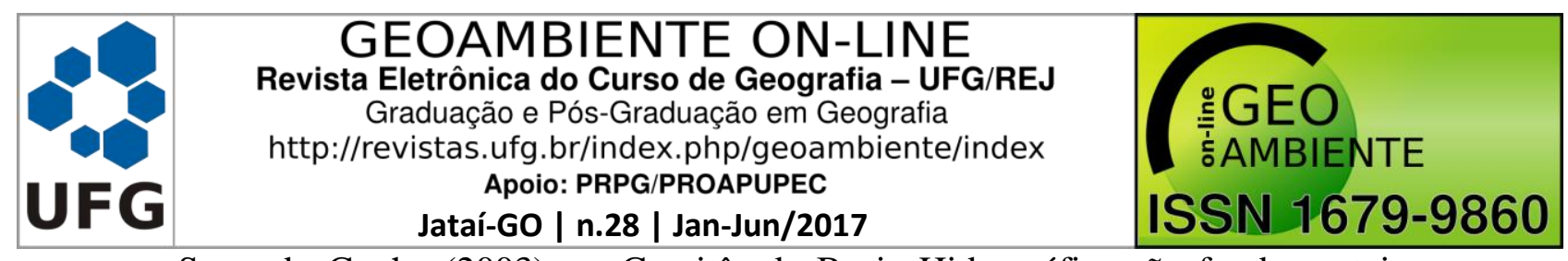

Segundo Cunha (2003), os Comitês de Bacia Hidrográfica são fundamentais para a implementação da Política Nacional dos Recursos Hídricos, pois envolve a sociedade em questões pertinentes aos usos da água, vista na atualidade como em fase de escassez.

Nos últimos anos, o surgimento e fortalecimento de vários conselhos consultivos e deliberativos nos níveis federal, estadual e municipal, tem contato com a participação ativa de representantes de organizações não governamentais e movimentos sociais. Tais participações tem se efetivando nos Conselhos de Meio Ambiente, nos Comitês de Bacias Hidrográficas (CBHs) e nas Áreas de Proteção Ambiental (APAs). Mas, em muitos casos, têm pouca influência no processo decisório, e a representação tem caráter bastante contraditório (JACOBI e BARBI, 2007).

Estas reflexões apontam um encaminhamento: a necessidade de associar a atuação do Estado, via políticas públicas, com as necessidades da sociedade civil, não apenas das grandes empresas capitalistas, mas sim do cidadão comum que vive uma realidade muitas vezes de exclusão social. Isto nos remete ao exposto por Mantovaneli Júnior (2006, p. 61) “(...) o grande desafio para o debate sobre as políticas públicas é, portanto, construir uma leitura onde o sistema político mostre-se indissociável do sistema social, como reclama a realidade social contemporânea".

\section{Considerações Finais}

- O questionamento do paradigma dominante de desenvolvimento atinge consequentemente sua base ideológica e conceitual. Do mesmo modo que a humanidade tenta implementar uma nova racionalidade na relação homem/meio, é importante definir como essa relação será definida, quem serão os responsáveis pelas decisões que durante muito tempo estava sobre o controle do capital.

- Como podemos ver nas últimas décadas houve no Brasil uma ampliação dos espaços oferecidos à participação social nos fóruns de decisão sobre o tipo de relação homem/meio que prevalecerá. Em que ritmo determinado recurso natural será explorado: ao ritmo da sede do capital ou ao ritmo das reais necessidades sociais, das populações locais ou de comunidades tradicionais?

- Talvez seja esse o grande debate a ser feito, e que a partir das legislações elaboradas recentemente, as vozes sociais ganharam um instrumento amplificador e se empoderaram. Mesmo assim não é fácil convencer da necessidade de se apropriar desses espaços abertos. Somos um país com uma experiência sempre interrompida de 


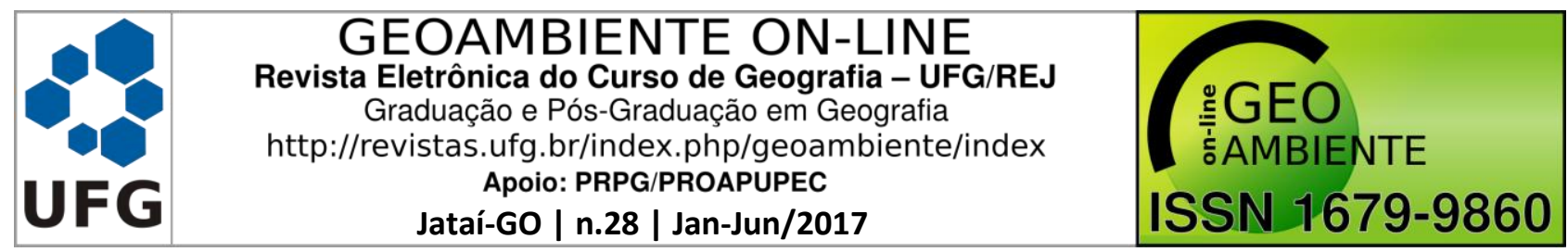

democracia e participação popular. Ao longo de nossa breve história republicana tivemos, por diversas vezes, nossas vozes caladas, nossos espaços fechados (PENTEADO, 2010). Talvez por essa razão tenhamos dificuldade de compreender que uma porta se abriu e que precisamos atravessá-la para conseguir nossa autodeterminação enquanto povos, populações e comunidades diversas.

- A legislação sobre recursos hídricos no Brasil, apresentou grande salto em termos de participação social, embora as dificuldades de participação equitativa sejam gigantescas face a pouca formação educacional da população. No entanto, o passo foi dado. Continuemos na busca por mais ações que realcem os interesses sociais de grande parte dos excluídos da população brasileira.

- Diante do exposto, dos avanços na gestão participativa e nas contradições que ainda permeiam tal processo, principalmente em função de interesse particulares e do limitado acesso ao conhecimento sistematizado por grande parte da população, retomamos as considerações de Leff (2009) ao afirmar que para ocorrer a efetivação de uma gestão participativa e democrática dos recursos naturais, uma nova racionalidade ambiental deve ser construída a partir da desconstrução da racionalidade capitalista na busca de uma economia baseada na equidade e sustentabilidade. Tal ponderação pode ser pensada como utópica ou como um desafio a ser alcançado no futuro breve.

\section{Referências}

BERNARDI, E. C. S, PANZIERA, A.G; BURIOL, G.A; SWAROWSKY. A. Bacia hidrográfica como unidade de gestão ambiental. Disciplinarum Scientia. Série: Ciências Naturais e Tecnológicas, Santa Maria, v.13, n.2, p. 159-168, 2012.

BRASIL. Lei n ${ }^{\circ} 9.433$ de 08 de janeiro de 1997. . Constituição Federativa do Brasil de 1988. . Decreto $\mathrm{n}^{\mathrm{o}} 24.643$, de 10 de julho de 1934. . Lei $\mathrm{n}^{\circ} 9.795$ de 27 de abril de 1999.

CARRERA-FERNANDEZ, J; GARRIDO, R. J. Economia dos recursos hídricos. Salvador: EDUFBA, 2002. 


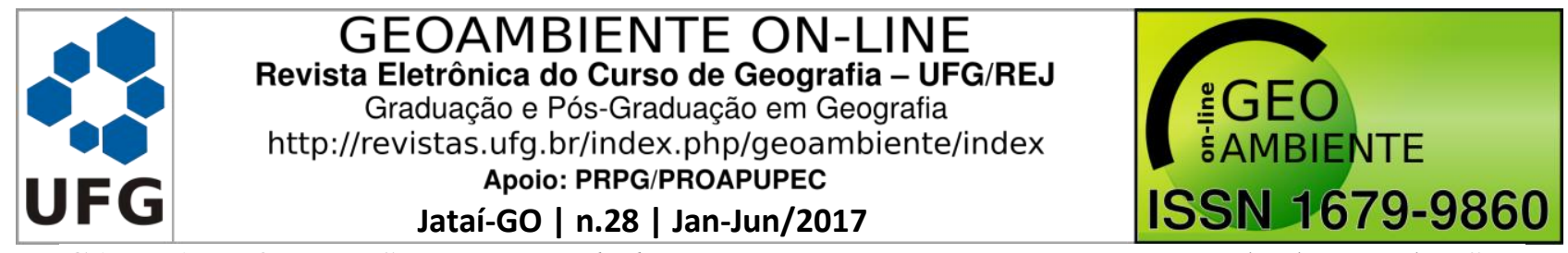

CARVALHO, M.E.S. A questão hídrica no Vaza Barris Sergipano. Tese de doutorado. São Cristóvão; UFS, 2010.

CUNHA, S. B. Bacias hidrográficas. In: CUNHA, S.B.; GUERRA, A.J.T. Geomorfologia do Brasil. 3.ed. Rio de Janeiro: Bertrand Brasil, 2003, p. 229-272.

GUERRA, A. J. T, et. al. Erosão e conservação dos solos. $2^{\mathrm{a}}$ ed. Rio de Janeiro, Bertrand Brasil, 2005.

JACOBI, P.R.; BARBI, F. Democracia e participação na gestão dos recursos hídricos no Brasil. Revista. Katálysis. Florianópolis, v. 10 n. 2 p. 237-244 jul./dez. 2007.

LEAL, A. C. Gestão das Águas no Pontal do Paranapanema/SP. Instituto de Geociências. Campinas: Universidade Estadual de Campinas. Tese de Doutorado. 2000.

LEFF, E. Complexidade, interdisciplinaridade e saber ambiental. In: JR, A. P; TUCCI, et. al. Interdisciplinaridade em ciências ambientais. São Paulo: Signus Editora, 2000, p. 19-51.

LEFF, E. Saber ambiental: sustentabilidade, racionalidade, complexidade, poder. 7.ed. Petrópolis: Vozes. Rio de Janeiro, 2009.

LISBOA, J. B. de. A trajetória do discurso do desenvolvimento para o Nordeste: políticas públicas na (dis)simulação da esperança. Aracaju: NPGEO/UFS, 2007. Tese de Doutorado.

MACHADO, C. J. S. Recursos Hídricos e cidadania no Brasil: limites, alternativas e desafios. Ambiente e Sociedade. Vol.VI, n.2, jul/dez, 2003, p.122-136.

MANTOVANELI JÚNIOR, O. Políticas Públicas no século XI: a perspectiva da gestão multicêntrica. Blumenau: EDIFURB, 2006.

MORIN, E. Sete saberes à uma educação do futuro. 2a ed. São Paulo: Cortez; Brasília: Unesco, 2000.

NOVAES, W. Meio ambiente no século XXI:21 especialistas falam da questão ambiental nas suas áreas de conhecimento. $2^{\mathrm{a}}$ ed. Campinas, SP, Armazém do Ipê, 2008.

OLIVEIRA, M. L.V.M. Águas do Ceará: política pública de territorialidades conflituosas. Tese de doutorado. Núcleo de Pós-Graduação em Geografia. São Cristóvão: UFS/NPGEO, 2010.

ONU, Agenda 21 Global. Organização das Nações Unidas. Rio de Janeiro. 1992 


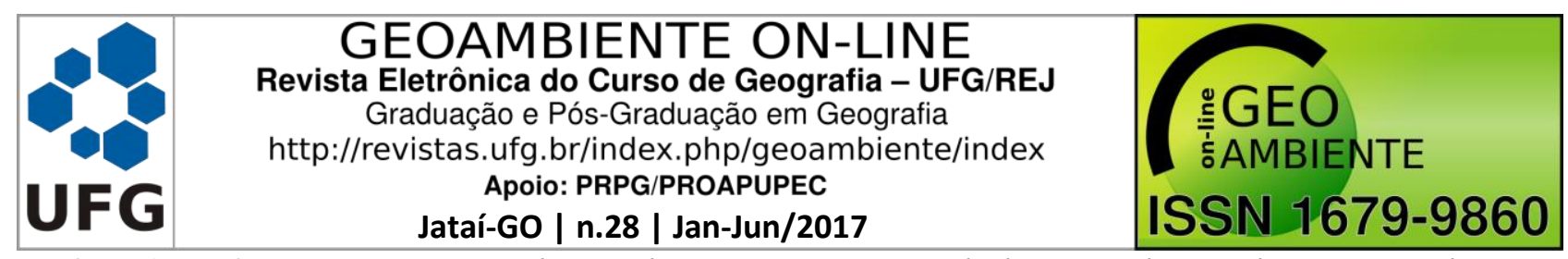

ORLANDO, P. H. K. A produção do espaço e gestão hídrica na bacia do rio Paraibuna (MG-RJ): uma análise crítica.Tese de Doutorado. Programa de pós-graduação em Geografia. Presidente Prudente: UNESP, 2006.

PENTEADO, H. D. Meio Ambiente e Formação de Professores. $7^{\mathrm{a}}$ ed. São Paulo: Cortez, 2010 .

PINHEIRO FILHO, J.D. Gestão hídrica: participação social e a institucionalização no Comite de bacia hidrografica do rio Ipojuca/PE. Dissertação de Mestrado. Recife: UFPE, 2005.

REBOUÇAS, A. Água doce no mundo e no Brasil. In: REBOUÇAS, Aldo; BRAGA, Benedito; TUNDISI, José Galizia (Org.). Águas doces no Brasil: capital ecológico, uso e conservação. 2.ed. São Paulo: Escrituras Editora, 2006, p. 1-35.

RIBEIRO, W. C. Geografia Política da Água. São Paulo: Annablume, 2008.

RODRIGUEZ, J. M. M; SILVA, E. V. A classificação das paisagens a partir de uma visão geossistêmica. Revista Mercator. Fortaleza, v. 1, n.1, 2002, p.95-120.

SETTI, A. Augusto; LIMA, J. E. F. W; Chaves, A.G.M; Pereira, I.C. Introdução ao gerenciamento de recursos hídricos. 2.ed. Brasília: Agência Nacional de Energia Elétrica, Superintendência de Estudos e Informações Hidrológicas, 2001.

SILVA, D. D; PRUSKI, F. F. Gestão de Recursos Hídricos: aspectos legais, econômicos, administrativos e sociais. Viçosa: Universidade Federal de Viçosa, 2005.

TRISTÃO, M. A educação ambiental na formação de professores: redes de saberes. 2. ed. São Paulo: Annablume, 2008.

TUNDISI, J. G. Água no século XXI: Enfrentando a escassez. $2^{\mathrm{a}}$ ed. São Carlos, RiMa, IIE, 2005. 